аспирант кафедры социологии

Российского университета дружбы народов

\section{КОНЦЕПЦИЯ КУЛЬТУРНОЙ ИДЕНТИЧНОСТИ В СОЦИОЛОГИИ}

\begin{abstract}
Аннотация:
В статье представлены точки зрения К. Хансена и других исследователей на концепцию культурной идентичности в социологии. Утверждается, что язык и история выступают в роли элементов формирования культурной идентичности. Культурная память рассматривается как фактор становления культурной идентичности. На основе анализа понятий идентичности и культуры представлен подход для определения изучаемой категории.
\end{abstract}

Ключевые слова:

культура, идентичность, культурная идентичность, культурная память, социология, социологический подход, социальная группа.
PhD student, Social Science Department, Peoples' Friendship University of Russia

\section{THE CONCEPT OF CULTURAL IDENTITY IN SOCIOLOGY}

The article deals with the viewpoints of $K$. Hansen and other sociologists on the concept of cultural identity in sociology. The author determines language and history as elements of formation of cultural identity. The article reviews cultural memory as a factor of development of cultural identity. Based on the analysis of the concepts of identity and culture, the paper presents an approach to determine the category under investigation.

Keywords:

culture, identity, cultural identity, cultural memory, sociology, sociological approach, social group.

Понятие культуры, как и понятие идентичности, может быть использовано для разнообразных целей, и, следовательно, его содержание часто меняется в зависимости от той или иной темы. В рамках фрилософиии, социологии, этнологии и междисциплинарных школ, таких как культурология, описано и охарактеризовано то, что можно понимать под культурой. Даже внутри конкретных дисциплин данная категория часто остается расплывчатой и дуалистичной. Теоретические трудности начинаются с многообразия фрорм культуры и заканчиваются парадоксами, возникающими в научной оценке френомена культуры. Культура - это конфигурация усвоенного поведения и его результатов, составные элементы которой разделяются и передаются членами общества [1, с. 82]. Культура часто описывается как ориентация либо стандартизация ценностей или способов поведения (т. е. как стандартизуемая). Кроме того, для индивидуальной изменчивости, субкультур и очень маленьких сообществ культура создается как интеллектуальный аспект искусственной среды в ходе социальной жизни [2, р. 43].

По мнению ученых, занимающихся проблемами межкультурной коммуникации, культурная идентичность - осознанное принятие человеком соответствующих культурных норм и образцов поведения, ценностных ориентаций и языка, понимание своего «я» с позиций тех характеристик, которые приняты в данном обществе, самоотождествление себя с культурными образцами именно этого социума [3, с. 54]. Уточняется, что культурная идентичность представляет собой совокупность конкретных устойчивых качеств, благодаря которым те или иные явления или люди вызывают у нас чувство симпатии или антипатии. В зависимости от этого мы выбираем, соответственно, тип, манеру и форму общения с ними.

«Диффреренциальная» (differenzlogische) концепция культуры, разработанная К. Хансеном, позволяет разрешить этот (кажущийся) парадокс. Вместо того чтобы рассматривать культуру как целостную сущность вслед за И.Г. Гердером, К. Хансен создает концепцию культуры, объясняющую ее единство на основе дифференцированного характера. Язык является не только отправной точкой или медиатором, благодаря чему имеет место речевое общение, но и тесно связан с восприятием и поиском причин. Язык не просто называет вещи, но присваивает им смысл, помещая их в контекст [4, р. 62]. Таким образом, в языке каждого сообщества запечатлено собственное восприятие реальной жизни, воспроизводятся значения, полученные на его языке, который в свою очередь способствует сплоченности и выступает в качестве механизма включения и исключения.

Также история представляет собой чрезвычайно значимую сферу. Она влияет на современную жизнь и устойчиво воздействует на мышление посредством традиций, исторических праздников и памятных дней. Язык и история взаимозависимы: с одной стороны, история передается с помощью языка, с другой - язык развивается на протяжении всей истории и изменяется в том числе в связи с историческими событиями. Язык и история способствуют сплоченности общества и составляют первичный фактор культурного влияния. Тем не менее в некотором роде это происходит 
непроизвольно, потому что достигается за счет рождения и социализации. Благодаря социализации, т. е. образованию, индивид не только изучает родной язык и постигает опыт, конкретную историю, имеющие отношение к обществу этого человека, но и включается в те или иные группы, участвует в организации социума и его институтов. Они символизируют закономерности для действий и рассуждений, а также базовые по значимости понятия, характерные для соответствующей культуры. Такая стандартизация составляет основу того, что члены культуры считают «нормальным». Право рождения может быть использовано для иллюстрации этих значений на основе стандартизации. Это микронормативные критерии: радушие, гостеприимство, приготовление специальной еды и напитков, принятие подарков и выражение благодарности.

Эмоциональные критерии столь же важны в этом отношении, как и другие - для принятия решений в каком-либо учреждении, поскольку они также служат для установления безопасного поведения. «Если кто-то не придерживается правил, взаимодействие прерывается, остальные пребывают в смятении, и его или ее могут счесть эксцентричным или даже сумасшедшим» [5, p. 84]. В большинстве случаев эти культурные нормы не выписаны в полном объеме, а приобретаются подсознательно в результате социализации. Этикет, этические и правовые нормы представляют собой исключения, поскольку некоторые из них могут быть сформулированы (этикет и этические нормы) или даже кодифицированы (правовые). Следовательно, культурная стандартизация, нормативные коллективные критерии имеют различные ограничительные последствия в зависимости от степени, в которой они были сформулированы (привычки, ценности, этические и правовые нормы).

В отличие от социальных рамочных условий (например, языка и истории) выбор имеющихся интерпретаций действий и смысла предлагает некоторую свободу в принятии решений, а именно в возможности высказываться за членство в группе и ее условия или против них. Как уже упоминалось, в связи с концепцией идентичности в культурах может быть любое количество групп или коллективов, при этом оно постоянно меняется. Кроме семейной общины, членство в которой устанавливается по праву рождения, существует множество других групп в большинстве стран, где членство и идентификация, в частности с определенного возраста и далее, являются добровольными и факультативными. Каждой группе присуща стандартизация. По словам К. Хансена, последняя применяется к установлению связи, мыслям, чувствам, поведению и действиям. Индивид свободен решать - в пределах своих обобществленных рамочных условий, среди существующих групп и общин, поступать на свое усмотрение, но его или ее решение (в пользу особых групп или против них) и действия (в пределах различных групп) не могут не иметь социальных последствий. Членство в одной группе может осложнить или даже исключить доступ к другим. По словам К. Хансена, поэтому возможен стресс: «Физические лица составляют группу, а группа формирует людей, которые приобретают свою идентичность в ответ на коллективные критерии». Взаимодействие между личностью и группой, по мнению К. Хансена, выражается следующим образом: «С одной стороны, культура [в виде коллективных норм] создается отдельными лицами, но, с другой стороны, она создает свою идентичность» [6, р. 139-140].

Культурная память тоже является фактором фрормирования культурной идентичности. В понятии «культурная память» фиксируется тот факт, что образы коллективной памяти представляют для социальной общности значительную ценность. Культурная память определяется Я. Ассманом как «орган ритуально оформленного неповседневного воспоминания». Поддержание коллективной идентичности предполагает регулярное обращение к образам культурной памяти.

Культурная память сохраняет запас знаний, из которого группа получает осознание собственных единства и своеобразия. Объективные проявления рассматриваемой категории определяются через вид или идентификационную детерминацию в положительном («мы есть это») или отрицательном («это наша противоположность») смысле [7].

Благодаря такой конкретизации идентичности развивается то, что Ф. Ницше назвал «конституцией или горизонтами». Предоставление знаний в культурной памяти характеризуется резкими различиями между теми, кто принадлежит, и теми, кто этого не делает, между тем, что принадлежит себе, и тем, что является иностранным. Доступ к этим знаниям и их передача контролируются не столько называемым Х. Блюменбергом «теоретическим любопытством», сколько «потребностью в идентичности», как описано Г. Молом [8].

Связав эти два понятия - идентичности и культуры, можно обозначить культурную идентичность как явление, способное вызвать ощущение самотождественности у народа, позволяющего ему определить свое место в транснациональном пространстве [9]. Прежде всего важно отметить, что группы и отдельные лица влияют друг на друга. Лица образуют группу, которая в свою очередь воздействует на отдельных лиц. Более того, эти люди достигают своей идентичности в тесном взаимодействии коллективных ценностей (формируются посредством связи между членами группы) и нормативной стандартизации, существующей в данной группе.

Для причисления себя к определенной группе используются символы, которые можно рассматривать как стандартизированные фракторы связи, мысли, чувства и поведения. Поскольку 
один человек принадлежит более чем к одной группе, культурная идентичность не может быть описана как фиксированное состояние, она постоянно фрормируется заново, обращаясь к тому или иному количеству возможных норм и ценностей группы (или не учитывая их).

\section{Ссылки:}

1. Линтон Р. Понятие культуры // Вопросы социальной теории. 2009. Т. 3, № 1. С. 79-94

2. Demorgon J., Molz M. Conditions and effects of the analysis of Culture and intercultural interaction. Gottingen ; Bern, 1996.

3. Грушевицкая Т.Г. Основы межкультурной коммуникации. М., 2003

4. Hansen K.P. Culture and Cultural Studies. No. 1. Tuebingen ; Basel, 1995.

5. Argyle M. Non-verbal communication in human social interaction. Indianapolis, 1972.

6. Hansen K.P. Op. cit. No. 3. Tuebingen ; Basel, 2003.

7. Культурная память в контексте формирования национальной идентичности России в XXI в. : коллективная монография / отв. ред. Н.А. Кочеляева. М., 2015. 168 с.

8. Assmann J., Czaplicka J. Collective Memory and Cultural Identity // Cultural History. 1995. No. 65. P. 125-133.

9. Лысак И.В. Проблема сохранения культурной идентичности в условиях глобализации // Гуманитарные и социальноэкономические науки. 2010. № 4. С. 91-95.

\section{References}

Argyle, M 1972, Non-verbal communication in human social interaction, Indianapolis

Assmann, J \& Czaplicka, J 1995, 'Collective Memory and Cultural Identity', Cultural History, no. 65, pp. 125-133, https://doi.org/10.2307/488538.

Demorgon, J \& Molz, M 1996, Conditions and effects of the analysis of Culture and intercultural interaction, Gottingen, Bern. Grushevitskaya, TG 2003, The fundamentals of intercultural communication, Moscow, (in Russian).

Hansen, KP 1995, Culture and Cultural Studies, no. 1, Tuebingen, Basel.

Hansen, KP 2003, Culture and Cultural Studies, no. 3, Tuebingen, Basel.

Kochelyaev, NA (ed.) 2015, Cultural memory in the context of the formation of the national identity of Russia in the 21st century, collective monograph, Moscow, 168 p., (in Russian).

Linton, R 2009, 'The concept of culture', Voprosy sotsial'noy teorii, vol. 3, no. 1, pp. 79-94, (in Russian).

Lysak, IV 2010, 'The problem of preserving cultural identity in the context of globalization', Gumanitarnyye $i$ sotsial'noekonomicheskiye nauki, no. 4, pp. 91-95, (in Russian). 